NBER WORKING PAPER SERIES

\title{
THE EFFECTS OF CHANGES IN STATE SSI SUPPLEMENTS ON PRE-RETIREMENT LABOR SUPPLY
}

\author{
David Neumark \\ Elizabeth T. Powers \\ Working Paper 9851 \\ http://www.nber.org/papers/w9851
NATIONAL BUREAU OF ECONOMIC RESEARCH 1050 Massachusetts Avenue Cambridge, MA 02138
July 2003

This research was supported by NIA grant 1-R01-AG17619-01A2. We thank Paula Kazi and Aaron Sparrow for outstanding research assistance. The views expressed herein are those of the authors and not necessarily those of the Public Policy Institute of California, the Department of Economics at Michigan State University, or the National Bureau of Economic Research

(C)2003 by David Neumark and Elizabeth T. Powers. All rights reserved. Short sections of text not to exceed two paragraphs, may be quoted without explicit permission provided that full credit including (C) notice, is given to the source. 
The Effects of Changes in State SSI Supplements on Pre-Retirement Labor Supply David Neumark and Elizabeth T. Powers

NBER Working Paper No. 9851

July 2003

JEL No. I3, J2, J3

\section{$\underline{\text { ABSTRACT }}$}

Because the Supplemental Security Income (SSI) program is means-tested, with both income limits and asset limits, those on the margin of eligibility for the elderly component of the program face incentives to reduce labor supply (or earnings) prior to becoming eligible. Our past research relying on cross-state variation in SSI benefits found evidence consistent with the predicted negative labor supply effects. However, a reliance on cross-state variation necessitated reliance on less-than-ideal control samples. In contrast, this paper uses CPS data covering a 22-year period, which permit identification of the effects of SSI from within-state, time-series variation in SSI benefits, using a better control sample. The evidence points consistently to negative effects of more generous SSI payments on the labor supply of likely SSI participants aged 62-64. The implied elasticities of labor supply with respect to benefits, for those with a high probability of SSI participation, are generally in the range of ! 0.2 to ! 0.3 , looking at both employment and hours of work.

David Neumark

Public Policy Institute of California

500 Washington Street

Suite 800

San Francisco, CA 94111

and NBER

neumark@ppic.org
Elizabeth T. Powers

Institute of Government and Public Affairs

and Department of Economics

University of Illinois at Champaign-Urbana

epowers@ad.uiuc.edu 


\section{$\underline{\text { I. Introduction }}$}

The Supplemental Security Income (SSI) program was begun in 1974 to provide a uniform federal safety net for the elderly, blind, and disabled. In addition, many states supplement the benefits payable under SSI. The SSI program is means-tested, with both income limits and asset limits. As such, those on the margin of eligibility for the elderly component of the program face incentives to reduce labor supply (or earnings) prior to becoming eligible. ${ }^{1}$ Although the effects of means-tested income support programs on labor supply have been widely researched in the context of welfare programs for younger individuals and families (e.g., Moffitt, 1992; Blank, 2002), little work has been done on what is effectively a welfare program for the elderly. In prior research, though, we used cross-state variation in the benefit payments available under SSI to identify the effects of SSI on the labor supply of potential SSI participants as they approach the age of eligibility, finding evidence of labor supply declines (Neumark and Powers, $2000)^{2}$

Our evidence that SSI creates disincentives for work and saving among older individuals is limited in two respects. First, the data from the Survey of Income and Program Participation (SIPP) that were used were for a small number of years in the mid-1980s to the early 1990s (1984, 1990, and 1991, to be exact). Second, the analysis was largely limited to using cross-state variation in SSI benefit levels to identify the effects of SSI, because there was little time-series variation in SSI benefits from 1984 to 1991. In contrast, this paper uses annual Current Population Survey (CPS) data covering 1979-2000 to study the effects of SSI on labor supply. This data source permits us to re-examine our earlier evidence on these effects using the same identification strategy over a much longer period. More importantly, the CPS data allow us to

\footnotetext{
${ }^{1}$ In contrast, these incentives are unlikely or less likely to play a role for participants in the disabled and especially the blind components of the program, which we generally ignore in this paper.

${ }^{2}$ Both the asset and income limits also create incentives to reduce saving near the age of eligibility. This paper does not study saving, but see Neumark and Powers (1998) for evidence that SSI also reduces saving.
} 
use an alternative strategy that exploits changes in SSI benefit levels over time, within states, and hence relies on a better control sample consisting of observations on individuals residing in the same state with similar likelihoods of SSI participation, in periods when SSI benefits differed.

\section{The SSI Program}

The SSI program was enacted by the U.S. Congress in 1972 and begun in 1974. Prior to that year, three separate programs established in the original Social Security Act of 1935 and its 1950 amendments provided means-tested assistance for individuals who were either ineligible for Social Security or whose Social Security benefits were inadequate: Old-Age Assistance, Aid to the Blind, and Aid to the Permanently and Totally Disabled. However, federal law established only broad guidelines for these three programs, and states had great flexibility in setting program rules and benefit levels (including assessing individuals' needs). SSI was established to provide a uniform income floor and common eligibility requirements, while states were free to supplement SSI payments subject to their own eligibility rules, with one exception noted below.

Three factors generate variation across states in SSI benefit levels. ${ }^{3}$ First, states can choose an optional benefit supplement. They can administer the supplemental program themselves, or choose to have the Social Security Administration administer their supplemental programs as long as they maintain the same eligibility rules as the federal program (except that they are allowed to exclude additional items from income in determining eligibility for the state supplement). Second, Congress imposed mandatory supplements to ensure that in no state would citizens already in state programs receive lower benefits in the federal program than they had previously received under the state program. Because these mandatory supplements did not apply to individuals first becoming eligible for SSI in 1974 or later, they now apply to very few

\footnotetext{
${ }^{3}$ The discussion here refers to cash benefits. Some states also fund other expenses for SSI recipients, such as group living facilities (Committee on Ways and Means, 2000).
} 
individuals. Since we study behavior of individuals approaching the age of eligibility for SSI, we never need to account for these mandatory supplements. Third, some constraints were imposed on states' ability to alter supplemental payments, as in 1976 Congress also mandated that states pass along cost-of-living increases in federal benefits (to avoid states cutting their benefits to offset these increases). States can choose to either keep benefit levels or total expenditures at least as high as the previous year in nominal terms. ${ }^{4}$ The state supplementation can be quite dramatic. As of January 2000, the maximum federal benefit was $\$ 512$ for individuals, and $\$ 769$ for couples (when both individuals are aged 65 or over). In that same year the maximum individual (couple) benefit was $\$ 874(\$ 1,297)$ in Alaska, $\$ 747(\$ 1,094)$ in Connecticut, and $\$ 692(\$ 1,229)$ in California. However, many states have far more moderate supplements and 25 had none.

SSI is a means-tested program. As a consequence, benefits are reduced by income from other sources, including Social Security, and by financial resources. The federal benefit reduction formula disregards the first $\$ 65$ of earned income, and above that reduces the SSI benefit by 50 cents for every $\$ 1$ of earned income. It also disregards the first $\$ 20$ of unearned income (including Social Security benefits) and above that reduces the SSI benefit dollar-fordollar with unearned income. Finally, the SSI benefit is reduced dollar-for-dollar with any other means-tested transfer income. ${ }^{5}$ The limitation on financial resources is imposed via an asset limit, above which the individual or couple is ineligible for any benefit. As of 2000 the federal

\footnotetext{
${ }^{4}$ These details come from U.S. Social Security Administration (2002) and U.S. Committee on Ways and Means (2000).

${ }^{5}$ In addition, income from certain home energy and support and maintenance assistance, Food Stamps, most federally-funded housing assistance, state assistance based on need, one-third of child support payments, income received infrequently or irregularly, and income from a few other sources is excluded when determining eligibility.
} 
limits were $\$ 2,000$ for individuals and $\$ 3,000$ for couples. ${ }^{6}$ As noted above, when states administer their own programs they have flexibility to set their own limits on and exclusions for income and assets. But in practice few states have different rules, and when they do the differences are typically minor (U.S. Social Security Administration, January 2000).

The SSI program is large. In December 2000 there were 1.3 million recipients in the aged component of the program (and overall, 2 million recipients aged 65 and over). About half of these 1.3 million recipients receive a federal benefit only, and about half receive at least some SSI benefit via a state supplementation. Total payments for the aged program in 2000 were approximately $\$ 4.8$ billion (overall SSI spending was $\$ 31.6$ billion), about 75 percent of which was in the form of federal benefits, and the remainder state supplements (U.S. Social Security Administration, 2001).

\section{Theoretical Framework}

In this section, we outline a basic theoretical framework demonstrating why SSI creates disincentives for labor supply, in the context of a simple two-period model of labor supply without saving or second period work. For further details and elaboration, see Neumark and Powers (2000).

An agent chooses consumption (c) and work hours (h) in the first period and consumption in the second to maximize utility, $\mathrm{u}\left(\mathrm{c}_{1}, 1-\mathrm{h}_{1}\right)+\delta \mathrm{u}_{\mathrm{R}}\left(\mathrm{c}_{2}\right)$, where $\delta$ is the intertemporal discount rate. Since all income is consumed each period, the single important choice variable is first period labor supply. (The budget constraint in period 1 , when the individual is too young for SSI, is $\mathrm{c}_{1}$ $=\mathrm{w}_{1} \mathrm{~h}_{1}$.) First period work hours affect second period retirement income by increasing Social Security and private pension benefits.

\footnotetext{
${ }^{6}$ The following assets are excluded from the limit: the prospective recipient's car, home, and the land the home is on; life insurance policies with a face value of up to $\$ 1,500$; burial plots for the individual and immediate family members; and up to $\$ 1,500$ in burial funds for the individual and his or her spouse.
} 
The key complicating feature in analyzing SSI policy is the nonlinearity of the period 2 budget constraint. Let $\mathrm{Y}_{0}$ be the amount of income in retirement that is pre-determined as of period 1 (e.g., the level of the Social Security benefit based on the agent's earnings history prior to period 1), and let $\mathrm{B}\left(\mathrm{w}_{1} \mathrm{~h}_{1}\right)$ be the additional retirement income in period 2 that depends on first period earnings ( $\mathrm{B}^{\prime}>0$ and $\mathrm{B}$ " $<0$ are assumed). If the agent does not participate in SSI, then the second period budget constraint is $\mathrm{c}_{2}=\mathrm{Y}_{0}+\mathrm{B}\left(\mathrm{w}_{1} \mathrm{~h}_{1}\right)$ (the "autonomous" budget constraint). If the agent participates in SSI, but second period income from non-SSI sources (i.e., $\mathrm{Y}_{0}+\mathrm{B}\left(\mathrm{w}_{1} \mathrm{~h}_{1}\right)$ ) is below the disregarded amount, then period 2 income is $Y_{0}+\mathrm{G}+\mathrm{B}\left(\mathrm{w}_{1} \mathrm{~h}_{1}\right)$ (where $\mathrm{G}$ is the maximum SSI benefit). If second period non-SSI income exceeds the disregard, then period 2 income is $\mathrm{G}+\mathrm{D}$ (where $\mathrm{D}$ is the disregard level), as long as the individual remains eligible for SSI, Note that if first period earnings generate too much post-retirement income, the agent will be ineligible for SSI, and period 2 income is $\mathrm{Y}_{0}+\mathrm{B}\left(\mathrm{w}_{1} \mathrm{~h}_{1}\right)$.

SSI generosity reduces work effort both infra- and infer-marginally. First, consider the infra-marginal effects of a small increase in $\mathrm{G}$ on the agent's optimal choice. If he optimally locates on the autonomous segment of the budget constraint, work effort is unaffected by SSI benefit generosity. If the agent optimally participates in SSI, there are two cases: either his private income exceeds the SSI disregard amount, or it does not. If his non-SSI retirement income is below the disregard amount, additional work leads to both increased first period consumption and second period (retirement) income, and one can readily show that under standard conditions, optimal work hours are decreasing in G. Under the assumption that utility is time-separable, for an SSI participant whose period 2 income exceeds the disregard, the only incentive to work is to maintain period 1 consumption, because additional private income in period 2 will be taxed away at a 100\% rate by the SSI program. Since SSI cannot be received in 
the first period, the benefit $\mathrm{G}$ cannot influence the labor supply choice. ${ }^{7}$

Due to the segmented budget constraint, one must also consider how changes in SSI generosity affect the labor supply choice infer-marginally. In Neumark and Powers (2000), we illustrate how an increase in G shifts both SSI-participation segments of the budget constraint out relative to the autonomous budget constraint, encouraging SSI participation and reducing work. In addition, an increase in $\mathrm{G}$ widens the range of work hours that produce no additional retirement income due to SSI policy, further discouraging work.

When saving is allowed and SSI also has an asset test, $\mathrm{B}(\cdot)$ can also be thought of as asset income, and the arguments developed above imply that saving to increase asset income postretirement will be discouraged (see Hubbard, et al., 1995, for a more complete development of the theory underlying the impact of asset tests on saving). Clearly if asset tests discourage saving they will also discourage the additional work needed to raise the stock of assets that would normally be drawn down during retirement. Moreover, assets that are drawn down prior to retirement can be used to offset reduced labor supply. Thus, with saving in the model the disemployment incentives of SSI are likely enhanced.

\section{Data}

We use March CPS files from 1980-2001. These files ask respondents about labor supply in the previous calendar year (usual weekly hours and weeks worked for the previous calendar year, which can also be used to code employment in the previous calendar year), as well as during the survey week (employment and hours worked). We examine results using both measures of employment and hours.

We restrict attention to male household heads, aged 60 and older. Those aged 65 and older are used to estimate a model for predicting the probability of SSI participation, based on

\footnotetext{
${ }^{7}$ Work hours can have no influence on period 2 utility, $\delta u_{R}(G+D)$.
} 
whether they received income from SSI in the previous calendar year. Those aged 60-64 are used to estimate the labor supply models. In all the estimations the data are weighted using the March CPS household weights.

To the CPS data we append information on SSI benefits at the state level. Through 1983 SSI benefits were set each July, and afterwards they were set in January. For the sample aged 65 and older that we use to predict SSI participation, we use marital status and the wife's current age to assign the benefit level for either individuals or couples. For the sample aged 60-64, for whom we will both predict SSI participation at age 65 and model contemporaneous labor supply, we assign the couple benefit if the individual is married and his wife is no more than three years younger than he. The idea here is that in assessing the benefits of SSI participation, the individual will consider the couples benefit level if his wife is sufficiently close in age (three years or fewer) that he will face the higher benefit level for most of the prospective retirement period. To keep things simple, when we are using labor supply measures for the survey week we use the SSI benefits that prevail in March of the current year, and when we use the labor supply measures for the previous calendar year we use the SSI benefits that were set in January of that calendar year (or, prior to 1984, the SSI benefits that were set in July of that year.)

As noted above and explained in more detail in the next section, we use both crosssection (across-state) and time-series (within-state) variation in SSI benefits. Nominal maximum state supplements for selected years, and measures of both of these types of variation, are reported in Table 1. Looking first at columns (1)-(3) and (1')-(3'), the table reveals that there has been and remains considerable variation in state supplements. Alaska, California, Colorado, and Connecticut have the highest benefits over the long haul, while numerous states have rather trivial supplements. The table also shows that there have been relatively few sharp changes in state supplements, with the most noticeable being Wisconsin's elimination of its supplement for 
couples as of $2000 .^{8}$

In addition to reporting the supplemental benefit levels, the table provides three measures of variation in benefits. The first is the real percentage change in the state supplement from 1985 to 2000 (columns (4) and (4')). For both individuals and couples these percentage changes vary widely. However, notice that the larger percentage changes (e.g., Washington, DC and South Dakota) occur for state supplements that are quite small. Thus, a more meaningful measure of changes in benefits is for the combined federal and state benefit. As shown in columns (5) and (5'), there is considerably less variation across states in these changes, although it is important to keep in mind that there is also variation relative to states with no supplementation of benefits, in which the real value of benefits was virtually unchanged over the sample period. Note, also, that in most states with supplements the real value of the combined state plus federal benefit declined over this period. Finally, for each state the table also shows the percentage difference between the total benefit in the state (state plus federal) and the federal benefit, in columns (6) and (6'). A comparison of these columns with those showing the time-series variation indicates that the across-state variation is far more dramatic. This suggests that the estimators that rely on the time-series (within-state) variation in benefits - while having some important advantages - are likely to have more difficulty in accurately estimating the effects of SSI.

\section{$\underline{\text { V. The Empirical Approach }}$}

We expect SSI to affect the work behavior of those with a relatively high likelihood of eligibility. To identify such individuals, we analyze samples of people aged 65 and over to identify the characteristics of likely SSI participants. Probit estimates derived from these older samples are then applied to the characteristics of workers under age 65 to assign a value of the

\footnotetext{
${ }^{8}$ We report the maximum benefit and use it in the empirical analysis, because we do not know the SSI payments that are actually received by individuals, and because these would be endogenous with labor supply.
} 
likelihood of future SSI participation to them. Those with a probability of participation above a particular cutoff are characterized as "likely participants," and the others as "unlikely participants." Relevant characteristics associated with SSI participation include education (a proxy for permanent income), race and other variables reflecting demographic heterogeneity, marital status (an indicator of the availability of support from a spouse and intervivos transfers from a network of relatives) and past welfare use (an indicator of stigma about using welfare, or of unobservables related to eligibility for or need of income-support programs). Frequently, the welfare literature has categorized individuals into treatment or control groups based on a single exogenous characteristic (e.g., family structure or education). Our framework can be viewed as broadening this approach to allow a multitude of exogenous factors to determine control and treatment group categorizations. ${ }^{9}$

As noted earlier, our previous research on this topic using data from the SIPP relied on cross-state variation in state SSI supplements. We used this variation to construct alternative "difference-in-differences" (DD) and "difference-in-difference-in-differences" (DDD) estimators. In the present research, we instead use a data set covering a longer time period, which lets us identify the effects of SSI from changes over time in states' supplemental SSI payments, using fixed state effects to control for any unmeasured state-related variables that might influence both labor supply and the generosity of SSI and hence bias the estimates relying on cross-state variation. This section first explains our earlier approach, and then explains and highlights the advantages of the approach taken in this paper.

To simplify the exposition, suppose that we can classify states at a point in time as paying

\footnotetext{
${ }^{9}$ Since these participation probabilities are properly considered a part of the model, thought must be given as to how their impact is identified in the analysis. First, the probabilities are estimated using a different sample from the sample whose labor supply and saving behavior we analyze. Second, the estimates are identified through functional form given the nonlinearity of the probit model. Third, when available in a data set, we use variables thought to be correlated with knowledge and use of the welfare system, but not directly influencing current saving and work decisions, such as previous lifetime experience with another welfare program (e.g., Food Stamps).
} 
either high or low benefits (think of low benefits as equivalent to no benefits). Then we can further partition the observations of likely and unlikely SSI participants into four groups: likely participants living in high- or low-benefit states, and unlikely participants living in high- or lowbenefit states. ${ }^{10}$

In addition to these basic distinctions, we can further subdivide these groups by age. We focus most on those aged 62-64 for three reasons. First, given stochastic influences on earnings and wealth, older workers can form better predictions of post-retirement income. Second, we suspect that workers pay more attention to the potential receipt of SSI benefits as they approach the eligibility age. ${ }^{11}$ Finally, as we show elsewhere (Powers and Neumark, 2003a and 2003b), the eligibility for early Social Security retirement benefits at age 62 likely enhances the labor supply disincentives of SSI beginning at age 62, and in other empirical work (Neumark and Powers, 2000) we found evidence of the sharpest labor supply effects for 62-64 year-olds. ${ }^{12}$

To set the stage, although it is not central to our analysis, we begin with the simple difference estimator. Let the labor supply measure be denoted Y, SUPP be a dummy variable for states that supplement the SSI benefit (indicating "generous" states), and X a vector of control variables (education, race, marital status, a dummy variable indicating that spouse is younger by more than three years, and the state unemployment rate in the corresponding year). Then the simple difference estimator for the sample of 62-64 year-old likely participants is

$$
\mathrm{Y}_{\text {is }}=\zeta+\alpha \cdot \mathrm{SUPP}_{\text {is }}+\mathrm{X}_{\mathrm{is}} \psi+\varepsilon_{\text {is }}
$$

In equation (1), $\alpha$ simply measures the difference in labor supply (Y) between likely

\footnotetext{
${ }^{10}$ This two-way dichotomous classification is useful for exposition. In the empirical analysis the specifications use continuous variation in benefit generosity.

${ }^{11}$ See Mitchell (1988) for related evidence regarding pensions, and Cagetti (1999) for related evidence with respect to saving.

${ }^{12}$ In our other work, the smaller data sets we used left us with quite small samples of 62-64 year-olds who were likely SSI participants. The much larger CPS lets us obtain much larger samples and more precise estimates for this age group.
} 
participants in states with generous supplements and likely participants in states without generous supplements. The ' $\mathrm{i}$ ' and 's' subscripts denote individuals and states. In fact we also estimate this specification pooling across multiple years, in which case a ' $t$ ' subscript would also be added, but we omit that subscript here to emphasize the contrast with the estimators below that exploit more fully the time-series variation in SSI benefits. We label this estimator SD.

If there are other sources of labor supply differences across states, these may spuriously be attributed to differences in SSI benefits, as this state-level variation may be correlated with SUPP. This concern led us to implement DD and DDD estimators that are based on the introduction of control groups to try to control for state-level labor supply differences across states. Specifically, we want control groups that will exhibit the same cross-state variation in labor supply as the older likely participants arising from factors other than SSI benefits. The effects of SSI can then be identified from the difference in the relationship between SSI benefits and labor supply between the older likely participants and a control group. We first discuss control groups that parallel our earlier work in relying only on cross-sectional variation in SSI benefits, and then move on to those that exploit within-state variation over time.

One way to control for these state-level state differences when there is primarily crosssectional variation in SSI supplements is to use data on younger individuals in the same state who are also likely participants, assuming that the state-level labor supply differences are common to likely participants across age groups. In this case the younger individuals control for these differences and the effects of SSI are identified from differences in labor supply between younger and older likely participants in high- vs. low-benefit states. Letting OLD be the dummy variable indicating those aged 62-64, we can then use a sample of, say, 60-64 year-olds to estimate the DD regression

$$
\mathrm{Y}_{\text {is }}=\zeta+\alpha \cdot \mathrm{SUPP}_{\text {is }} \cdot \mathrm{OLD}_{\text {is }}+\beta \cdot \mathrm{SUPP}_{\text {is }}+\gamma \cdot \mathrm{OLD}_{\text {is }}+\mathrm{X}_{\text {is }} \psi+\varepsilon_{\text {is }} .
$$


In this regression, $\beta$ picks up the difference in $Y$, assumed common to all ages, between states with and without generous SSI supplements. $\gamma$ captures the difference in $\mathrm{Y}$, common to all states, between 60-61 and 62-64 year-olds. $\alpha$ now captures the extent to which the difference in Y between 60-61 and 62-64 year-olds differs in states with generous SSI supplements, relative to states without generous supplements, focusing only on likely participants. We label this estimator DD-CS. ${ }^{13}$

Of course, the DD-CS estimator could still rest on invalid identifying assumptions. In particular, DD-CS identifies the effect of SSI from the extent to which the difference in Y for likely participants in high-supplement states vs. low-supplement states is greater (or less) for 6264 year-olds than for 60-61 year-olds. But if the slope of the age profile of labor supply is different in high-supplement states for other reasons, we may be identifying an effect of something other than SSI. We can solve this problem if we also use the unlikely participants to capture state-specific differences in age profiles. This difference-in-difference-in-difference (DDD) estimator requires the assumption that state-specific factors affecting the slopes of age profiles of labor supply are common to likely and unlikely participants in a state. In this case, we use the sample of all 60-64 year-olds, and estimate the effect of SSI from the regression

$$
\begin{aligned}
\mathrm{Y}_{\text {is }}=\zeta & +\alpha \cdot \mathrm{SUPP}_{\text {is }} \cdot \mathrm{PART}_{\text {is }} \cdot \mathrm{OLD}_{\text {is }}+\beta \cdot \mathrm{SUPP}_{\text {is }}+\gamma \cdot \mathrm{OLD}_{\text {is }}+\delta \cdot \mathrm{PART}_{\text {is }} \\
& +\theta \cdot \mathrm{SUPP}_{\mathrm{is}} \cdot \mathrm{OLD}_{\text {is }}+\kappa \cdot \mathrm{SUPP}_{\text {is }} \cdot \mathrm{PART}_{\text {is }}+\lambda \cdot \mathrm{OLD}_{\mathrm{is}} \cdot \mathrm{PART}_{\mathrm{is}}+\mathrm{X}_{\mathrm{is}} \psi+\varepsilon_{\mathrm{is}} \cdot
\end{aligned}
$$

In this regression $\beta$ again picks up the difference in $Y$ between states with and without generous SSI supplements, $\gamma$ captures the difference between 62-64 and 60-61 year-olds, and $\delta$ measures the difference between likely and unlikely participants. The simple interactions capture the differences between older and younger individuals in high- vs. low-supplement states

\footnotetext{
${ }^{13}$ In some of our earlier work we also used men aged 40-59 as a control group. The closer age group should provide a better control group as their behavior is more likely to be the same except for the influence of SSI.
} 
$(\theta)$, likely and unlikely participants in high- vs. low-supplement states ( $\kappa)$, and 62-64 year-old likely participants vs. unlikely participants $(\lambda)$. What $\alpha$ identifies, then, is the extent to which the difference in $\mathrm{Y}$ between 62-64 year-old and 60-61 year-old likely participants, relative to the difference between 62-64 year-old and 60-61 year-old unlikely participants, varies between highand low-supplement states. Thus, $\alpha$ identifies the effect of SSI after netting out state-specific variation in changes in labor supply with age. We denote this estimator DDD-CS to indicate that it is a DDD estimator that can be estimated using only the cross-state variation in SSI benefits.

There is also an alternative DD estimator that controls for state-specific differences in labor supply using individuals in the state who are of the same age, but who are unlikely participants. However, we have more confidence in those with characteristics associated with likely participation serving as a control group for the labor supply behavior of 62-64 year-old likely participants. Reflecting this (we believe), in other work we have done exploiting administrative Social Security Administration records matched to SIPP data to estimate similar specifications, we found that among the two alternative DD estimators, only the one using the younger likely participants as the control yielded strong evidence of employment disincentives from SSI (Neumark and Powers, 2002).

Naturally, this raises questions about using unlikely participants as a second level of control in the DDD estimator. Indeed, this concern is part of the reason for turning to a data set that allows us to exploit time-series variation in state supplemental SSI benefits, as the timeseries variation allows the implementation of different estimators using different control groups to account for spurious sources of associations between SSI and pre-retirement labor supply, and in particular allows a DDD estimator that does not rely on using the unlikely participants as a control.

The estimators described thus far can be implemented with a single cross-section or with 
repeated cross-sections and are the ones we use in Neumark and Powers (2000). ${ }^{14}$ With repeated cross-sections, time-series variation in benefits played a role, but because our repeated crosssections covered a short time period, the primary source of variation was across states. As noted in the Introduction, however, in this paper we use data covering a much longer time span and therefore are interested in exploiting the time-series variation in SSI benefits more fully.

To see the advantages afforded by this time-series variation, consider first the SD estimator in equation (1). We noted that this estimator is potentially problematic because of state-level differences in labor supply of older individuals that could be correlated with SSI benefits. The estimator DD-CS attacks this problem by introducing a control group from the same cross-sectional data set from which the older individuals are taken —in particular, younger likely participants. An alternative is to use observations on likely participants in the same age group, but from different years when SSI benefits were at different levels. This entails estimating equation (1) for multiple years, with state dummy variables (STATE) to capture the state-level differences, and year dummy variables (YEAR) to capture common changes over time, as in

$$
\mathrm{Y}_{\text {ist }}=\zeta+\alpha \cdot \mathrm{SUPP}_{\text {ist }}+\mathrm{STATE}_{\text {is }} \pi+\mathrm{YEAR}_{\text {it }} \rho+\mathrm{X}_{\text {ist } \psi}+\varepsilon_{\text {ist }},
$$

where we have added a ' $t$ ' subscript to emphasize using the time-series variation in SSI benefits. This is an alternative DD estimator, which we denote DD-TS since it uses time-series observations from other periods in the same state to generate the control group. In this model $\pi$ captures state-specific differences in labor supply, and $\rho$ captures differences over time common to states. The DD estimator $\alpha$ then identifies the effects of SSI from the differences in changes over time across states with different changes in SSI benefit generosity.

\footnotetext{
${ }^{14}$ When implemented with repeated cross-sections, year fixed effects are included to absorb time-series fluctuations in labor market outcomes common to all states.
} 
The DD estimators DD-TS and DD-CS are based on different assumptions as to what observations provide the best control group to capture state-level differences in labor supply that might generate a spurious correlation between SSI benefits and the labor supply of older likely SSI participants. We are inclined to prefer DD-TS because it uses observations on exactly the same types of individuals - likely participants aged 62-64 - to obtain a control group. On the other hand, as noted in the discussion of Table 1, there is not a tremendous amount of time-series variation in SSI benefits, and as the time horizon gets longer we have to be concerned about the comparability of behavior of older individuals many years apart.

The estimator DD-TS identifies the effects of SSI from whether labor supply of older likely participants changes by more in states that increase their benefits than in states that do not. ${ }^{15}$ However, just as in the case of DD-CS there is a concern with a spurious relationship between SSI benefits and labor supply—which motivated the DDD-CS estimator — so too is there a similar concern in the case of DD-TS. Since this latter estimator uses time-series variation, however, the concern is that there are changes over time in labor supply that are spuriously correlated with time-series changes in benefit generosity. In that case, we again want to introduce a control group that we believe will exhibit the same time-series changes in labor supply as the older likely participants that are attributable to factors other than SSI, so that the effects of SSI can be identified from differences in changes in labor supply between older likely participants and the control group associated with changes in SSI benefits. Paralleling the earlier discussion, we can use younger likely participants in the same state, with the regression model

$$
\begin{aligned}
\mathrm{Y}_{\text {ist }}=\zeta & +\alpha \cdot \mathrm{SUPP}_{\text {ist }} \cdot \mathrm{OLD}_{\text {ist }}+\beta \cdot \mathrm{SUPP}_{\text {ist }}+\gamma \cdot \mathrm{OLD}_{\text {ist }}+\mathrm{STATE}_{\mathrm{is}} \pi+\mathrm{YEAR}_{\text {it }} \rho \\
& +\mathrm{OLD}_{\text {ist }} \cdot \mathrm{STATE}_{\mathrm{is}} \theta+\mathrm{OLD}_{\text {ist }} \cdot \mathrm{YEAR}_{\mathrm{it}} \kappa+\mathrm{X}_{\text {ist }} \psi+\varepsilon_{\text {ist }} \cdot
\end{aligned}
$$

\footnotetext{
${ }^{15}$ While we have couched the explanations of the estimators in terms of a dummy variable for generous benefits, clearly this analysis will be more meaningful in terms of continuous variation in benefits.
} 
In this model $\theta$ captures fixed differences across states between the labor supply of younger and older likely participants. This parallels the addition of older and younger unlikely participants to the DD-CS estimator to allow for the possibility that there were differences in the labor supply profile associated with variation in SSI benefits. There the variation was across states, so these differences were captured by differencing relative to the profile for unlikely participants; here the variation is over time, so these differences are captured by differencing relative to the profile in other years for the same states. $\kappa$ captures differences in the common time-series changes in labor supply for older (versus younger) likely participants. The DDD estimator $\alpha$ then measures the difference in the change in labor supply of older versus younger likely participants associated with changes in SSI benefits. We denote this estimator DDD-TS. An important advantage of this estimator relative to DDD-CS is that it does not rely at all on using data on unlikely participants, a group which, as we noted above, may not be an ideal control group. The various estimators discussed in this section and used in the next section are summarized in Table 2.

\section{$\underline{\text { VI. Results }}$}

\section{Descriptive Statistics and Predictors of SSI Participation}

Descriptive statistics for the samples of 62-64 and 60-61 year-old men are reported in the first two columns of Table 3. All four labor supply measures reveal significant drop-offs after age 61; for example, the current employment rate falls from 64.6 to 45.1 percent. On other dimensions, of course, these subsamples are very similar.

Estimates of the probit model used to predict SSI participation, which in turn is used to select a group of likely SSI participants for analysis, are presented in column (3); the estimates have been transformed into marginal effects. SSI participation is based on whether the individual reported income from SSI in the past year. In the CPS, there is no way of knowing 
that the individual was originally a participant in the aged component of the SSI program. In principle it would be desirable to drop those with a disability — who might be receiving SSI under the disabled or blind components of the program - from the analysis. But information on disability is elicited only for those not employed, so that this information is a function of the dependent variables used in some of our analyses.

In the SSI participation model, all of the estimates are strongly statistically significant. Not surprisingly, the real value of the SSI benefit is positively associated with SSI participation. The magnitude of the estimate implies that a $\$ 100$ increase in monthly benefits (about a 25 percent increase relative to the sample mean) raises the participation probability by 0.0064 , a 20 percent increase relative to the participation rate of men aged 65 and over of 0.0316 , implying an elasticity of 0.85 . We would expect that variables positively related to lifetime income or wealth, as well as current earning opportunities, would be negatively associated with SSI participation. This is borne out in the negative effect of education, and the positive effect of black and the state unemployment rate. Similar to what we found in SIPP data, we find that through 11 years of schooling higher education is associated with a lower likelihood of SSI participation; participation is lower for those with 12 or more years of schooling, although the marginal effect of education beyond high school is minimal. This was apparent in a specification with much more-detailed education controls, and is captured in the specification reported here (and used throughout) by including an interaction between years of education and a dummy variable for less than a high school education, as well as a dummy variable for a high school education or more. ${ }^{16}$ In addition, given that never married men typically earn less than divorced, widowed, or separated men, who in turn earn less than married men, net of other controls

\footnotetext{
${ }^{16}$ For the estimates reported in column (3), for example, relative to someone with eight years of schooling the probability of participation is lower by 0.007 for someone with ten years of schooling, 0.011 for someone with 11 years of schooling, and 0.036 for someone with 12 or more years of schooling.
} 
(Korenman and Neumark, 1991), as we expect never married men are considerably more likely to participate in SSI, and divorced, widowed, or separated men somewhat more likely. Finally, perhaps reflecting both resources and heterogeneity with respect to willingness to take-up public support programs, Food Stamp recipients are more likely to participate in SSI.

We use the estimates of this model to predict the probability of SSI participation of 6064 year-olds, so that we can identify likely participants. ${ }^{17}$ For most of our analyses, we use a cutoff of the $90^{\text {th }}$ centile of the distribution of predicted probabilities of SSI participation to identify these likely participants. As reported in the last row of column (3), the $90^{\text {th }}$ centile of the distribution is a 0.035 probability of participation. This is, of course, a relatively low probability, but there are no doubt many determinants of SSI participation that are unobserved to the researcher, so that many individuals at this predicted probability have a much higher probability in fact. In addition, the estimated probability of participation climbs sharply above the $90^{\text {th }}$ centile, to 0.084 at the $95^{\text {th }}$ centile and 0.470 at the $99^{\text {th }}$ centile. But using a cutoff such as the $99^{\text {th }}$ would yield too small a sample for analysis. If we use the top decile of the distribution, and one-third of these individuals actually participate, that would apparently account for most participants, since the actual participation rate for those aged 65 and over in the sample is 0.032 . But given that some participants are likely to come from lower down in the distribution, in analyses of the robustness of the results we also experiment with using the $70^{\text {th }}$ and $80^{\text {th }}$ centiles. Conversely, to examine the sensitivity of the estimates to using a more stringent cutoff, we also report results using the $95^{\text {th }}$ centile.

\section{Labor Supply Estimates-Graphical Analysis}

Prior to presenting the regression results, in order to help cement the intuition underlying

\footnotetext{
${ }^{17}$ To keep the "treatment" and "control groups" the same, when we predict these probabilities we net out the SSI supplement, so that individuals in states with different supplements but with identical characteristics (as captured in the other controls) are assigned the same probability of participation. For the same reason, we do not include fixed state effects in the participation probits, since these would reflect in large part cross-state variation in SSI benefits.
} 
the central estimators a graphical display of the data and illustration of some of these estimators is presented in Figure 1. The upper row of Figure 1 illustrates the simple difference (SD) estimator and the difference-in-differences estimator (DD-CS), which rely on cross-state variation in SSI supplements. To construct these plots we use the sample of likely participants. We define by the vector $\mathrm{Z}$ all of the control variables in $\mathrm{X}$ in equation (1), as well as the year dummy variables. We then regress both the labor supply measure (usual weekly hours) and the combined state and federal SSI benefit on Z, and form the residuals. We then plot the residuals from the labor supply regression against the residuals from the SSI benefit regression. This is informative because the regression coefficient from the simple regression for these residuals is exactly the coefficient that would result from estimating equation (1).

The upper-left-most panel simply presents the residual scatter plot for likely participants aged 62-64 over the entire sample period. As indicated by the solid line, the simple regression of the residual hours measure on the residual SSI benefit, which is the SD estimator, is positively sloped, rather than negatively sloped as predicted by the theory. The center panel in the upper row presents the same scatter plot, but for 60-61 year-old likely participants. Recall that the younger likely participants are used as the control sample in the DD-CS estimator. The regression line for this group also slopes upward. The upper-right-hand panel graphs the difference in slopes between the regression lines for the 62-64 year-olds and the 60-61 year-olds. This is the DD-CS estimator. It is downward sloping. The downward slope arises because in the first two scatter plots labor supply rises less quickly with the SSI benefit for the 62-64 year-olds than for the 60-61 year-olds. Assuming that the regression line for the 60-61 year-olds reflects unmeasured state differences associated with both labor supply and SSI benefits, it is the difference between the two slopes of the regression lines that identifies the effect of SSI. As shown in the right-hand panel (with a different scale), the difference between these slopes yields 
the negative effect that is predicted by the theory.

The bottom row of graphs displays the DD-TS and DDD-TS estimators that rely on timeseries variation in SSI benefits within states. The observations plotted in these graphs are similar to those in the top row of graphs, except that prior to running the regressions and calculating the residuals, all of the variables are demeaned relative to their state-specific means-precisely the transformation that is done for the fixed effects or within-group estimator. The lower-left-most graph displays the scatter plot of the residuals from these regressions for the within-state deviations of hours and benefits (i.e., the deviations of the individual data from the state means computed over all years) for 62-64 year-old likely participants. The regression line through these points is the DD-TS estimator. It is downward sloped, consistent with the theoretical prediction. The second panel in the bottom row is the parallel scatter plot for 60-61 year-olds. It too is downward sloped. If there were unmeasured changes over time associated with both changes in labor supply and in SSI benefits, then these 60-61 year-olds serve as a control sample for this analysis, and the DDD-TS estimator is the difference between these slopes. Such changes are plausible, because employment among older men was falling over this period for a host of reasons, and SSI benefits were also falling in real terms, which would generate a positive correlation between changes in labor supply and changes in SSI benefits. But because the downward slope is less steep for the 60-61 year-olds, the third graph in the bottom row, which displays the DDD-TS estimate, is negatively sloped (note that the scale is different), again consistent with the theory.

\section{Labor Supply Estimates-Regression Analysis}

Regression results from implementing each of the alternative estimators described in Section V and summarized in Table 2 are reported in Table 4. The first three rows report estimates that rely on cross-sectional (cross-state) variation in SSI benefits. In the SD estimates 
of the effect of SSI on labor supply, reported in the first row, three of the four estimates are positive, but none are statistically significant. However, when the 60-61 year-olds are used as a control sample, in the DD-CS estimates in the second row, the estimates become negative, and for the labor supply measures from the previous calendar year these estimated labor supply effects are statistically significant (although one at only the ten-percent level). We expect the results for the previous year's measures to be stronger, as these likely reflect more permanent behavior than labor supply measures for a single week. The final cross-sectional estimator is the DDD-CS estimator, which compares the differences between 62-64 year-old and 60-61 year-old likely participants to the differences between the 62-64 year-old and 60-61 year-old unlikely participants. These estimates are quite similar to those from the DD-CS estimator; all are negative, and again the estimates for the previous year's labor supply measures are statistically significant, although only at the ten-percent level.

The final two rows of Table 4 report the results from the new estimators using the timeseries variation in SSI benefits within states. The DD-TS estimator using only the 62-64 yearolds yields negative but insignificant estimates. But the preferred DDD-TS estimator, which compares the relationship between labor supply and benefit changes for 62-64 versus 60-61 yearolds, yields much stronger evidence of negative effects of SSI benefits on labor supply. For three of the four labor supply measures the estimated effects are statistically significant, one at the one-percent level, one at the five-percent level, and one at the ten-percent level. Again, the stronger evidence emerges for the labor supply measures that cover the entire previous calendar year, rather than just the survey week. Interestingly, the stronger evidence from the DDD-TS estimator results mainly from smaller standard errors rather than different coefficient estimates.

Using the estimates for the calendar year labor supply measures, for the employment measures the estimated magnitude implies that a $\$ 100$ increase in monthly SSI benefits (or a 
$\$ 1,200$ increase in annual benefits) reduces the employment rate by 0.05 . Based on the figures in Table 3 , this implies an elasticity of -0.36 , which considering that this applies only to likely participants does not seem like an unreasonable magnitude. For hours, the same increase in benefits reduces hours by 1.87 , implying a similar elasticity of -0.34 .

Table 5 presents some robustness analyses of the estimators using time-series variation in SSI benefits. The first panel of Table 5 varies from the last two rows of Table 4 only by dropping the CPS sample weights. All of the estimates remain negative, although the estimated labor supply effects decline a bit in absolute value in almost every case. But for the previous year's labor supply measures the DDD-TS estimates remain statistically significant. ${ }^{18}$

The next three panels vary the cutoff of the predicted probability of SSI participation used to identify likely participants, using two lower cutoffs (the $70^{\text {th }}$ and $80^{\text {th }}$ centiles), and one higher cutoff (the $95^{\text {th }}$ centile). Although we emphasize the DDD-TS estimators more, it is worth noting that for the alternative cutoffs there is some variation in whether the DD-TS estimate of the effects of SSI on labor supply is negative. But looking at the results for the DDD-TS estimator, whatever cutoff is used there is evidence of negative labor supply effects of higher SSI benefits. Perhaps most interesting, in the DDD-TS estimates the magnitudes of the labor supply effects generally indicate stronger negative effects the higher the cutoff, and this is always true going from the $80^{\text {th }}$, to the $90^{\text {th }}$, to the $95^{\text {th }}$ centile (the size of the effect is flipped for the $70^{\text {th }}$ versus $80^{\text {th }}$ comparison in two of the four cases, although the differences are small). For example, the results for employed last year indicate that a $\$ 100$ increase in SSI benefits is associated with a reduction in this probability of 0.018 using the $70^{\text {th }}$ centile, 0.027 using the $80^{\text {th }}$ centile, 0.050 using the $90^{\text {th }}$ centile (Table 4), and 0.064 using the $95^{\text {th }}$ centile. Moreover, the

\footnotetext{
${ }^{18}$ Note that the sample sizes change somewhat. That occurs because in the weighted estimates the $90^{\text {th }}$ centile cutoff is computed based on weighted data, so the actual number of observations above this cutoff can differ from the unweighted data. The sample sizes can also differ slightly across changes in the specification of the SSI participation probit because of ties at the centiles used as cutoffs.
} 
statistical evidence is considerably stronger using the highest cutoff, as for the $95^{\text {th }}$ centile all four of the labor supply estimates are statistically significant (one at the ten-percent level only). Qualitatively, we would expect to find stronger labor supply disincentives for more likely participants, as those more likely to participate should be more responsive to the incentives posed by SSI. ${ }^{19}$

Finally, in our work with the SIPP we examined results excluding those with workimpairing disabilities, because among disabled men younger than 65 there may be some negative labor supply response to higher SSI payments for the disabled in high-benefit states. As noted earlier, we cannot identify those with a work-impairing disability in the CPS, except for the nonemployed. Instead, we drop from the 60-64 year-old sample those reporting any SSI income. Assuming this income flows to the respondent, and not to his spouse or another family member, receipt of SSI income is an indicator of disability. The results are reported in the final panel of Table 5, and are very similar to the otherwise comparable estimates in Table 4.

\section{$\underline{\text { VII. Conclusions }}$}

Economic theory suggests that increased generosity of SSI payments will induce some labor supply reductions among older individuals who are approaching the age of eligibility for SSI and have sufficiently low resources that these labor supply reductions will help keep postretirement income and assets below the levels that would make them ineligible. This effect is likely to be particularly noticeable beginning at age 62 , when potential future SSI recipients can replace the income lost from reducing labor supply by taking early social security retirement; also note that there will be no long-lasting early retirement "penalty" since these are negated

\footnotetext{
${ }^{19}$ This prediction is not hard and fast, because it is conceivable that the margin on which SSI has its strongest effect on labor supply is for those with less than the highest likelihood of participation, and not for those who will participate under almost any circumstances. However, recall that even the $95^{\text {th }}$ centile of the distribution of predicted probabilities of SSI participation was less than 0.1 , so it is likely that throughout the range of cutoffs we consider we are focusing on those whose behavior may well be influenced by the size of the SSI benefit.
} 
once the household gets on SSI at age 65 .

Past research relying on cross-state variation in SSI benefits found evidence consistent with the predicted negative labor supply effects. However, a reliance on cross-state variation necessitated reliance on less-than-ideal control samples. In contrast, this paper uses CPS data covering a 21-year period, hence permitting identification of the effects of SSI from within-state, time-series variation in SSI benefits, using a control sample of individuals of similar ages, in the same states, and with similar probabilities of participating in SSI.

The evidence points consistently to negative effects of more generous SSI payments on the labor supply of likely SSI participants aged 62-64. The implied elasticities of labor supply with respect to benefits, for those with a high probability of SSI participation, are generally in the range of -0.2 to -0.3 , looking at both employment and hours of work.

These negative labor supply effects do not imply that more generous SSI payments constitute unwise social policy. Such incentives are an unavoidable consequence of insurance against reaching old age with very low economic resources. It is likely, however, that these negative labor supply effects are exacerbated by the low income and asset levels below which retirees must fall to be eligible for SSI (infer-marginal incentives), and by the 100-percent confiscation of Social Security income in the SSI formula (infra-marginal incentives). While bounds are necessary to target the most needy, the negative labor supply effects prior to eligibility for SSI (and the negative savings effects we have found in our other work) indicate that the income and asset limits have the perverse effect of inhibiting the accumulation of resources - however minimal - by the economically-disadvantaged elderly. Thus, while these findings do not lead to any clear implications regarding how SSI ought to be structured, they highlight the tradeoffs inherent in structuring and targeting this particular social insurance program. It is probably worth thinking about alternative ways of structuring SSI that would 
increase incentives to accumulate economic resources without generating large and costly increases in eligibility for SSI. In considering such alternatives, policy-makers may be able to exploit the inherent limitations to growth in the SSI rolls provided by social security. In particular, at least insofar as increased resource accumulation is reflected in greater social security wealth, potential SSI recipients become ineligible for SSI or eligible for reduced SSI payments as their social security benefits increase. 


\section{$\underline{\text { References }}$}

Blank, Rebecca M. 2002. "Evaluating Welfare Reform in the United States.” Journal of Economic Literature, Vol. 40, No. 4, December, pp. 1105-66.

Cagetti, Marco. 1999. "Wealth Accumulation Over the Life Cycle and Precautionary Savings." Unpublished paper, University of Virginia.

Committee on Ways and Means, U.S. House of Representatives. 2000. The 2000 Green Book (Washington, DC: U.S. Government Printing Office).

Hubbard, R. Glenn, Jonathan Skinner, and Stephen P. Zeldes. 1995. "Precautionary Saving and Social Insurance.” Journal of Political Economy, Vol. 103, No. 2, April, pp. 360-99.

Korenman, Sanders, and David Neumark. 1991. "Does Marriage Really Make Men More Productive?” Journal of Human Resources, Vol. 26, No. 2, Spring, pp.282-307.

Mitchell, Olivia S. 1988. "Worker Knowledge of Pension Provisions.” Journal of Labor Economics, Vol. 6, No. 1, January, pp. 21-39.

Moffitt, Robert. 1992. "Incentive Effects of the U.S. Welfare System: A Review." Journal of Economic Literature, Vol. 30, No. 1, pp. 1-61.

Neumark, David, and Elizabeth Powers. 1998. "The Effect of Means-Tested Income Support for the Elderly on Pre-Retirement Saving: Evidence from the SSI Program in the U.S." Journal of Public Economics, Vol. 68, No. 2, May, pp. 181-206.

Neumark, David, and Elizabeth Powers. 2000. "Welfare for the Elderly: The Effects of SSI on Pre-Retirement Labor Supply.” Journal of Public Economics, Vol. 78, No. 1/2, June, pp. 51-80.

Neumark, David, and Elizabeth T. Powers. 2002. "SSI and Labor Supply: Improved Evidence from Social Security Administrative Files.” Public Policy Institute of California Working Paper No. 2002-03.

Powers, Elizabeth T., and David Neumark. 2003a. "The Supplemental Security Income Program and Incentives to Claim Social Security Retirement Early: Empirical Evidence from Matched SIPP and Social Security Administrative Files.” Unpublished paper, University of Illinois.

Powers, Elizabeth T., and David Neumark, 2003b. "The Interaction of Public Retirement Programs in the U.S." American Economic Association Papers and Proceedings, Vol. 93, No. 2, May, pp. 261-65.

U.S. Social Security Administration. 2002. Understanding Supplemental Security Income.

U.S. Social Security Administration. 2001. Social Security Bulletin Annual Statistical Supplement. 
U.S. Social Security Administration. January 2000. State Assistance Programs for SSI Recipients. 


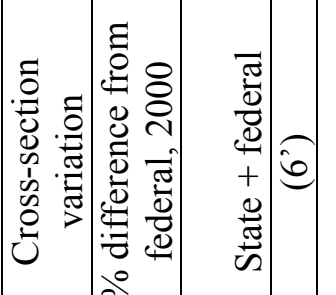

gิ

d

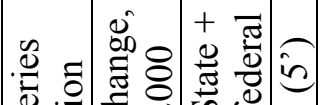

$\varphi_{1}^{\infty}=0$

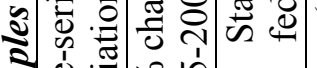

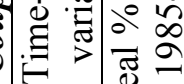

$\approx$

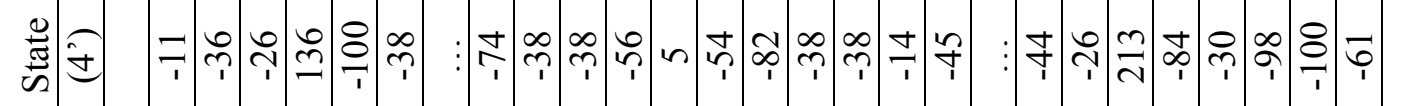

ஓ)

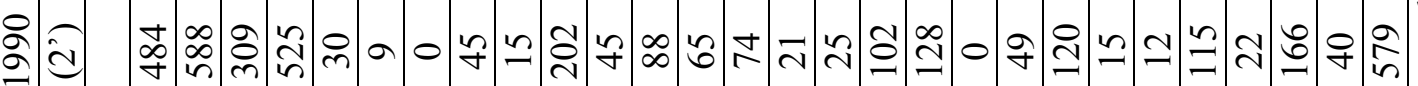

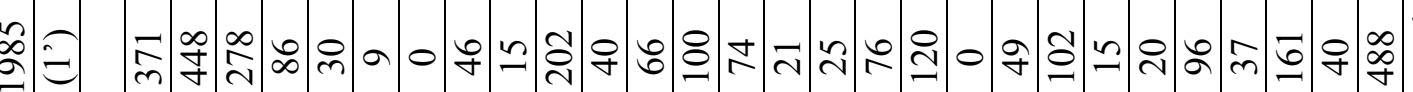

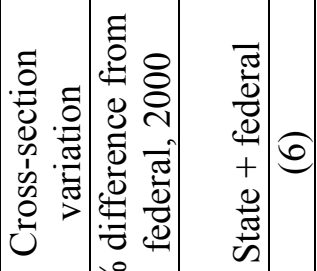

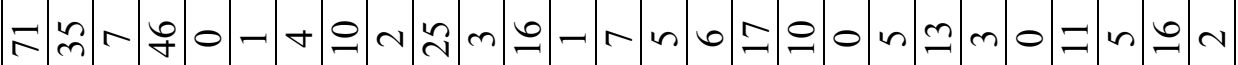

$\Xi \quad 0^{\circ}$

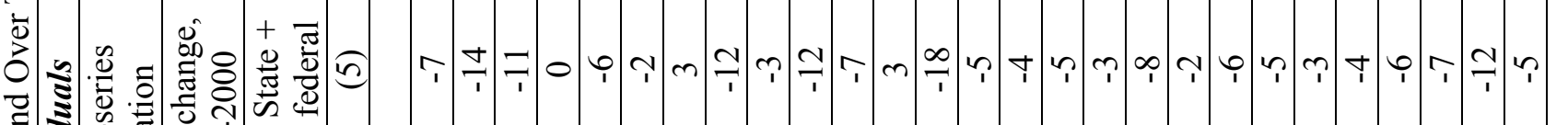

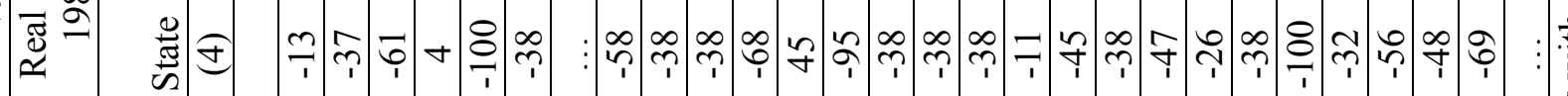

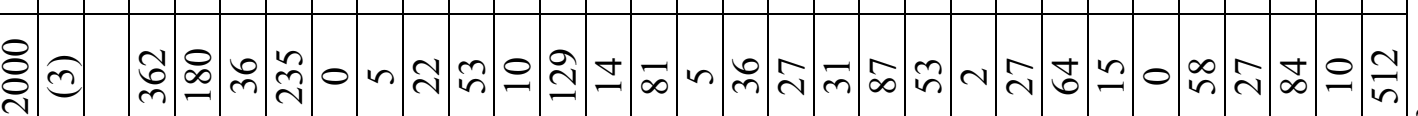

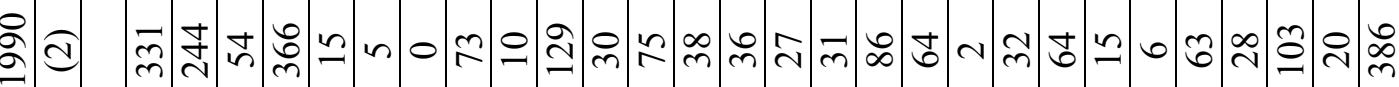

ص

全

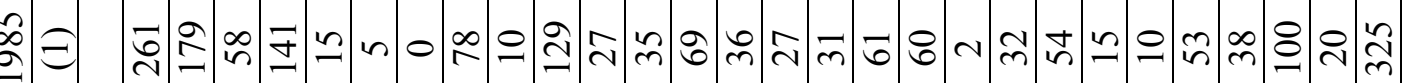

శิ 


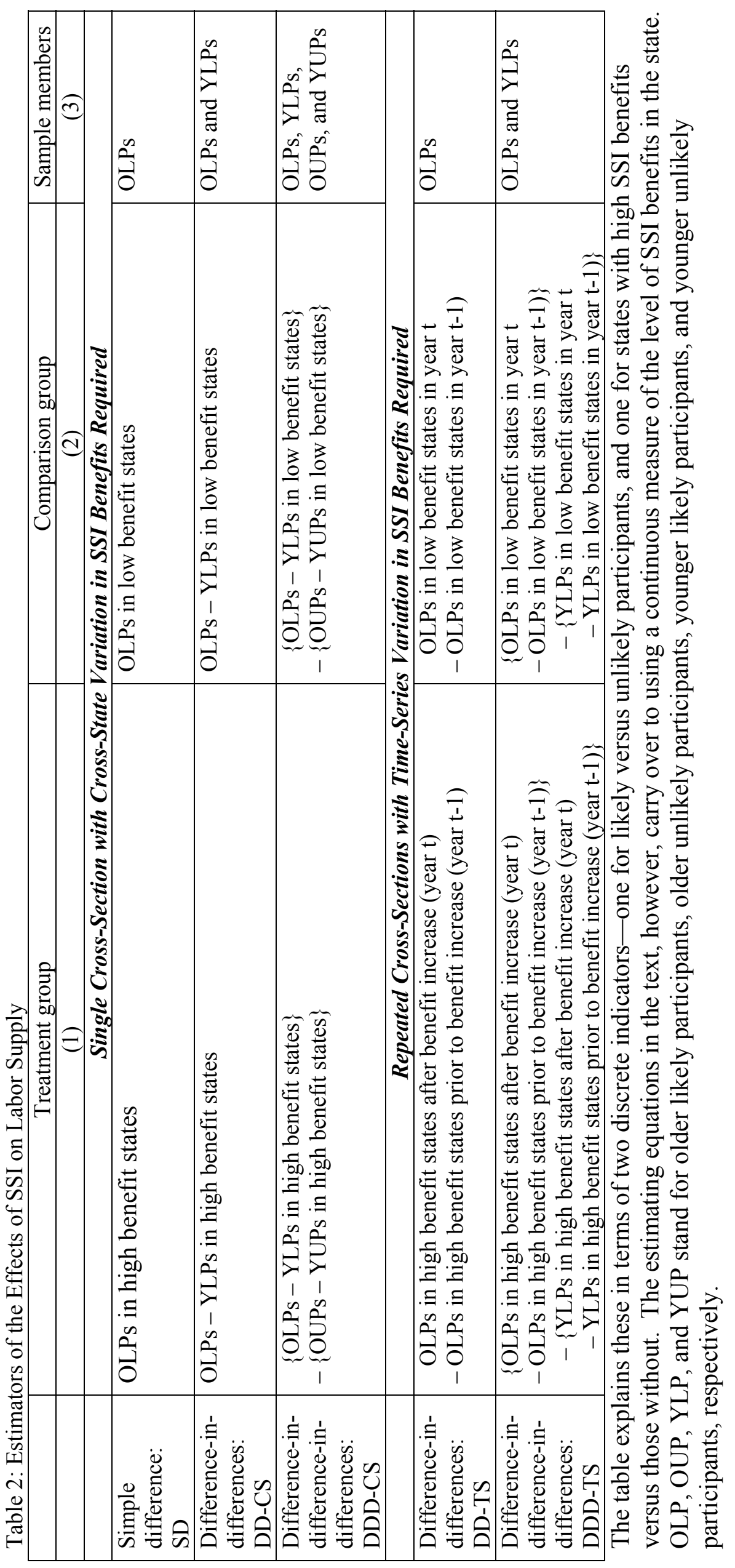


Table 3: Descriptive Statistics and Probit Estimates for SSI Participation

\begin{tabular}{|c|c|c|c|c|c|}
\hline \multirow{7}{*}{$\begin{array}{l} \\
\text { Currently employed (\%) } \\
\text { Employed last year (\%) } \\
\text { Hours last week } \\
\text { Usual weekly hours last year }\end{array}$} & \multicolumn{2}{|c|}{$\begin{array}{c}\text { Descriptive statistics, } \\
\text { all male heads of household }\end{array}$} & \multirow{2}{*}{$\begin{array}{c}\text { Probit for SSI } \\
\text { participation }\end{array}$} & \multicolumn{2}{|c|}{$\begin{array}{c}\text { Descriptive statistics, } \\
\text { likely participants }\end{array}$} \\
\hline & Ages 62-64 & Ages 60-61 & & Ages $62-64$ & Ages $60-61$ \\
\hline & $(1)$ & (2) & (3) & (4) & $(5)$ \\
\hline & 45.1 & 64.6 & & 28.0 & 38.6 \\
\hline & 58.1 & 73.7 & & 39.4 & 49.5 \\
\hline & 16.5 & 25.4 & & 9.1 & 14.2 \\
\hline & 23.0 & 30.8 & & 14.7 & 19.7 \\
\hline $\begin{array}{l}\text { Real maximum monthly } \\
\text { federal plus state SSI } \\
\text { payment (1982-84 \$) }\end{array}$ & 419.43 & 422.78 & $\begin{array}{c}0.0064 \\
(0.0002)\end{array}$ & 362.49 & 370.85 \\
\hline Education (years) & 11.9 & 12.1 & & 6.6 & 6.7 \\
\hline Education $\mathrm{x}$ less than high & & & -0.0035 & & \\
\hline school education & & & $(0.0001)$ & & \\
\hline $\begin{array}{l}\text { High school education or } \\
\text { more }\end{array}$ & & & $\begin{array}{l}-0.0639 \\
(0.0021)\end{array}$ & & \\
\hline Black & $7.5 \%$ & $7.9 \%$ & $\begin{array}{c}0.0039 \\
(0.0010)\end{array}$ & $26.1 \%$ & $24.2 \%$ \\
\hline Never married & $4.0 \%$ & $3.7 \%$ & $\begin{array}{c}0.0384 \\
(0.0034)\end{array}$ & $17.9 \%$ & $18.8 \%$ \\
\hline $\begin{array}{l}\text { Divorced, widowed, or } \\
\text { separated } \\
\text { Eligible for married couple } \\
\text { benefit (married \& wife age } \\
65+\text { ) }\end{array}$ & $12.9 \%$ & $11.7 \%$ & $\begin{array}{l}0.0111 \\
(0.0011) \\
-0.0156 \\
(0.0010)\end{array}$ & $31.1 \%$ & $26.2 \%$ \\
\hline $\begin{array}{l}\text { Received Food Stamps last } \\
\text { year }\end{array}$ & $3.3 \%$ & $3.6 \%$ & $\begin{array}{c}0.2420 \\
(0.0068)\end{array}$ & $32.2 \%$ & $38.1 \%$ \\
\hline State unemployment rate $(\%)$ & 6.4 & 6.4 & $\begin{array}{c}0.0017 \\
(0.0002)\end{array}$ & 7.1 & 7.2 \\
\hline $\begin{array}{l}\text { Number of observations } \\
\text { Mean participation } \\
\text { probability }\end{array}$ & 31,728 & 22,587 & $\begin{array}{c}135,901 \\
0.0316\end{array}$ & 3,501 & 2,314 \\
\hline $\begin{array}{l}90^{\text {th }} \text { centile of predicted } \\
\text { probability for } 60-64 \text { year- } \\
\text { olds }\end{array}$ & & & 0.0352 & & \\
\hline
\end{tabular}

In column (3), the marginal effects implied by the probit estimates are reported; standard errors are reported in parentheses, with t-statistics scaled to equal those in the probit estimation. The standard errors are adjusted to be robust to heteroscedasticity of the error term across clusters defined by state and year, and to arbitrary correlations of the error terms within these clusters. The probit includes fixed year effects. In the probit estimation, the SSI benefit is divided by $\$ 100$, so the marginal effect can be interpreted as arising from a $\$ 100$ increase in monthly benefits. When computing predicted probabilities, the supplement variable was set to its sample mean. Married heads with no corresponding spouse record in the CPS were excluded from all analyses. The omitted marital status category is married heads with younger spouses. 
Table 4: Alternative Estimators of the Effect of SSI Benefits on Employment and Hours

\begin{tabular}{|l|c|c|c|c|}
\hline & $\begin{array}{c}\text { Currently } \\
\text { employed }\end{array}$ & $\begin{array}{c}\text { Employed } \\
\text { last year }\end{array}$ & $\begin{array}{c}\text { Hours worked last } \\
\text { week }\end{array}$ & $\begin{array}{c}\text { Usual weekly } \\
\text { hours last year }\end{array}$ \\
\hline & $(1)$ & $(2)$ & $(3)$ & $(4)$ \\
\hline Cross-sectional estimators & & & & \\
SD: equation (1) & $0.007(0.011)$ & $-0.009(0.011)$ & $0.495(0.434)$ & $0.062(0.469)$ \\
& {$[\mathrm{N}=3,499]$} & {$[\mathrm{N}=3,501]$} & {$[\mathrm{N}=3,499]$} & {$[\mathrm{N}=3,501]$} \\
DD-CS: equation (2) & $-0.007(0.013)$ & $-0.028(0.013)^{* *}$ & $-0.110(0.510)$ & $-1.013(0.551)^{*}$ \\
& {$[\mathrm{~N}=5,813]$} & {$[\mathrm{N}=5,815]$} & {$[\mathrm{N}=5,813]$} & {$[\mathrm{N}=5,815]$} \\
DDD-CS: equation (3) & $-0.003(0.015)$ & $-0.025(0.014)^{*}$ & $-0.176(0.539)$ & $-1.156(0.597)^{*}$ \\
& {$[\mathrm{~N}=54,276]$} & {$[\mathrm{N}=54,315]$} & {$[\mathrm{N}=54,276]$} & {$[\mathrm{N}=54,315]$} \\
Within-state estimators & & & & \\
DD-TS: equation (4) & $-0.029(0.028)$ & $-0.043(0.031)$ & $-0.862(1.062)$ & $-1.822(1.297)$ \\
& {$[\mathrm{N}=3,489]$} & {$[\mathrm{N}=3,501]$} & {$[\mathrm{N}=3,499]$} & {$[\mathrm{N}=3,501]$} \\
DDD-TS: equation (5) & $-0.034(0.017)^{*}$ & $-0.050(0.019)^{* * *}$ & $-0.992(0.692)$ & $-1.869(0.749)^{* *}$ \\
& {$[\mathrm{~N}=5,803]$} & {$[\mathrm{N}=5,815]$} & {$[\mathrm{N}=5,813]$} & {$[\mathrm{N}=5,815]$} \\
\hline
\end{tabular}

The SSI benefit is divided by $\$ 100$, so the marginal effect can be interpreted as the effect of a $\$ 100$ increase in monthly benefits. The SSI benefit is aligned with the labor supply measure, so in columns (1) and (3) the benefit is for the year of the survey, and in columns (2) and (4) the benefit is for the prior year. The equations include controls for education, race, marital status, the state unemployment rate, and year, as well as the variables for SUPP, PART, and their interactions as explained in Section V. Only the estimates of the parameter $\alpha$ in equations (1)-(5) are reported. Standard errors of the estimates are reported in parentheses. The standard errors are adjusted to be robust to heteroscedasticity of the error term across clusters defined by state, year, age (when 60-61 year-olds are included), and likely participation (when unlikely participants are included), and to arbitrary correlations of the error terms within these clusters. '*', '**”, and '***' indicate that the estimate is statistically significant at the ten-, five-, or one-percent level. All specifications use a continuous measure of the SSI benefit, and the $90^{\text {th }}$ centile cutoff for predicted probability of SSI participation. 
Table 5: Robustness Analysis of Within-State Estimators of the Effect of SSI Benefits on Employment and Hours

\begin{tabular}{|c|c|c|c|c|}
\hline & $\begin{array}{l}\text { Currently } \\
\text { employed }\end{array}$ & $\begin{array}{c}\text { Employed } \\
\text { last year }\end{array}$ & $\begin{array}{c}\text { Hours worked last } \\
\text { week }\end{array}$ & $\begin{array}{l}\text { Usual weekly } \\
\text { hours last year }\end{array}$ \\
\hline & $(1)$ & $(2)$ & (3) & $(4)$ \\
\hline Unweighted & & & & \\
\hline DD-TS & $\begin{array}{c}-0.012(0.024) \\
{[\mathrm{N}=3,254]}\end{array}$ & $\begin{array}{c}-0.037(0.030) \\
{[\mathrm{N}=3,266]}\end{array}$ & $\begin{array}{c}-0.487(0.974) \\
{[\mathrm{N}=3,264]}\end{array}$ & $\begin{array}{c}-1.858(1.258) \\
{[\mathrm{N}=3,266]}\end{array}$ \\
\hline DDD-TS & $\begin{array}{c}-0.025(0.016) \\
{[\mathrm{N}=5,423]}\end{array}$ & $\begin{array}{c}-0.038(0.017)^{* *} \\
{[\mathrm{~N}=5,436]}\end{array}$ & $\begin{array}{c}-0.599(0.626) \\
{[\mathrm{N}=5,433]}\end{array}$ & $\begin{array}{c}-1.474(0.701)^{* *} \\
{[\mathrm{~N}=5,436]}\end{array}$ \\
\hline $\begin{array}{l}70^{\text {th }} \text { centile cutoff for predicted } \\
\text { probability of SSI participation }\end{array}$ & & & & \\
\hline DD-TS & $\begin{array}{c}0.006(0.017) \\
{[\mathrm{N}=10,234]}\end{array}$ & $\begin{array}{c}0.002(0.019) \\
{[\mathrm{N}=10,236]}\end{array}$ & $\begin{array}{c}-0.064(0.555) \\
{[\mathrm{N}=10,234]}\end{array}$ & $\begin{array}{c}0.041(0.796) \\
{[\mathrm{N}=10,236]}\end{array}$ \\
\hline DDD-TS & $\begin{array}{c}-0.022(0.010)^{* *} \\
{[\mathrm{~N}=16,944]}\end{array}$ & $\begin{array}{c}-0.018(0.010)^{*} \\
{[\mathrm{~N}=16,949]}\end{array}$ & $\begin{array}{c}-0.831(0.416)^{* *} \\
{[\mathrm{~N}=16,944]}\end{array}$ & $\begin{array}{c}-0.771(0.428)^{*} \\
{[\mathrm{~N}=16,949]}\end{array}$ \\
\hline $\begin{array}{l}80^{\text {th }} \text { centile cutoff for predicted } \\
\text { probability of SSI participation }\end{array}$ & & & & \\
\hline DD-TS & $\begin{array}{c}0.001(0.026) \\
{[\mathrm{N}=6,898]}\end{array}$ & $\begin{array}{c}0.018(0.029) \\
{[\mathrm{N}=6,903]}\end{array}$ & $\begin{array}{c}0.502(1.150) \\
{[\mathrm{N}=6,898]}\end{array}$ & $\begin{array}{c}0.574(1.226) \\
{[\mathrm{N}=6,903]}\end{array}$ \\
\hline DDD-TS & $\begin{array}{c}-0.019(0.013) \\
{[\mathrm{N}=11,463]}\end{array}$ & $\begin{array}{c}-0.027(0.014)^{*} \\
{[\mathrm{~N}=11,467]}\end{array}$ & $\begin{array}{c}-0.747(0.558) \\
{[\mathrm{N}=11,463]}\end{array}$ & $\begin{array}{c}-1.071(0.576)^{*} \\
{[\mathrm{~N}=11,467]}\end{array}$ \\
\hline $\begin{array}{l}95^{\text {th }} \text { centile cutoff for predicted } \\
\text { probability of SSI participation }\end{array}$ & & & & \\
\hline DD-TS & $\begin{array}{c}0.007(0.034) \\
{[\mathrm{N}=1,661]}\end{array}$ & $\begin{array}{c}0.002(0.041) \\
{[\mathrm{N}=1,673]}\end{array}$ & $\begin{array}{l}0.212(1.455) \\
{[\mathrm{N}=1,672]}\end{array}$ & $\begin{array}{c}0.270(1.839) \\
{[\mathrm{N}=1,673]}\end{array}$ \\
\hline DDD-TS & $\begin{array}{c}-0.056(0.021)^{* * *} \\
{[\mathrm{~N}=2,856]}\end{array}$ & $\begin{array}{c}-0.064(0.025)^{* *} \\
{[\mathrm{~N}=2,869]}\end{array}$ & $\begin{array}{c}-1.607(0.846)^{*} \\
{[\mathrm{~N}=2,867]}\end{array}$ & $\begin{array}{c}-1.948(0.983)^{* *} \\
{[\mathrm{~N}=2,869]}\end{array}$ \\
\hline Excluding current SSI recipients & & & & \\
\hline DD-TS & $\begin{array}{c}-0.036(0.028) \\
{[\mathrm{N}=3,127]}\end{array}$ & $\begin{array}{c}-0.048(0.032) \\
{[\mathrm{N}=3,134]}\end{array}$ & $\begin{array}{c}-1.006(1.079) \\
{[\mathrm{N}=3,133]}\end{array}$ & $\begin{array}{c}-1.973(1.374) \\
{[\mathrm{N}=3,134]}\end{array}$ \\
\hline DDD-TS & $\begin{array}{c}-0.031(0.018)^{*} \\
{[\mathrm{~N}=5,170]}\end{array}$ & $\begin{array}{c}-0.050(0.019)^{* * *} \\
{[\mathrm{~N}=5,176]}\end{array}$ & $\begin{array}{c}-0.821(0.729) \\
{[\mathrm{N}=5,176]}\end{array}$ & $\begin{array}{c}-1.847(0.788)^{* *} \\
{[\mathrm{~N}=5,176]}\end{array}$ \\
\hline
\end{tabular}

See notes to Table 4. Specifications correspond to those in Table 4 aside from the exceptions noted. 

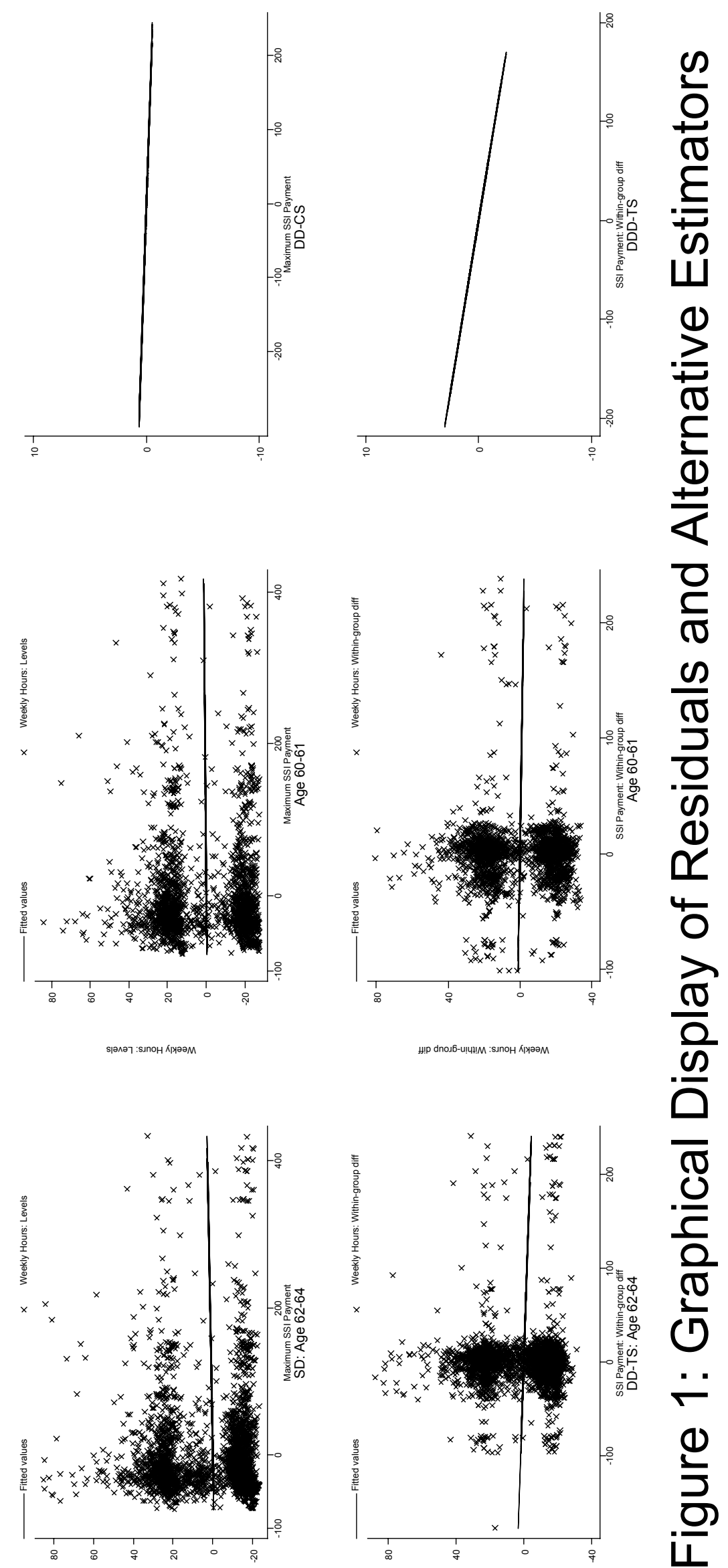